\title{
NAS TRAMAS E FALÁCIAS DO PLANEJAMENTO URBANO ESTRATÉGICO: MARKETING URBANO, MODELO BARCELONA E MEGAEVENTOS
}

\author{
THE FALLACIES OF STRATEGIC URBAN PLANNING: URBAN MARKETING, \\ BARCELONA MODEL, AND MEGA-EVENTS
}

\author{
LAS FALACIAS DE LA PLANIFICACIÓN ESTRATÉGICA: MARKETING \\ URBANO, MODELO BARCELONA Y MEGAEVENTOS
}

\author{
Ernandy Luis Vasconcelos de Lima - University of Oxford - Oxford - Reino Unido \\ ernandy@gmail.com
}

\begin{abstract}
Resumo
Frequentemente, considerados como catalisadores de transformação urbana, os megaeventos têm sido associados, outrossim, como ensejo de projetar globalmente as cidades-sede. À luz desse fenômeno, tanto 0 fascínio pelo planejamento estratégico, quanto o processo de regeneração urbana desvelado, sobretudo, por meio da edição dos Jogos Olímpicos de 1992, instigaram a atenção de diversos agentes no modelo Barcelona. Neste sentido, este artigo retoma a discussão crítica acerca da transformação urbana vivenciada pela cidade catalã, ponderando os impactos das preparações do megaevento esportivo Barcelona'92 no acesso à moradia, nas remoções e desalojos dos grupos afetados. Trata-se, enfim, de compreender como o planejamento estratégico esboçado em Barcelona impôs toda sorte de eventos, planos e programas resultantes de coalizões públicas e privadas. Além disso, o presente artigo analisa a trajetória das implicações sócio-territoriais do megaevento esportivo espanhol por meio de uma reflexão precipuamente geográfica.

Palavras-chave: modelo Barcelona, megaeventos e remoções, marketing urbano, planejamento urbano estratégico.
\end{abstract}

\section{Abstract}

Mega-events are often considered to be catalysts of urban transformation. They are perceived as a great opportunity to advertise the host cities globally. Therefore, focusing on the Barcelona model, the strategic urban planning and urban regeneration built upon the 1992 Olympic Games have become a model for several stakeholders. This paper intends to critically examine the strategies and implications of the Barcelona model, urban development, and renewal schemes in the Catalan capital. More specifically, it aims to provide a critical geographic analysis of the impacts of such schemes on the residents. Furthermore, it could give us clues about the extent to which the urban renewal changes taken place in Barcelona affected the core of what constitutes public governance practices and urban entrepreneurialism.

Key words: Barcelona model, mega-events and evictions, urban marketing, strategic urban planning.

\section{Resumen}

Megaeventos son a menudo considerados como catalizadores de transformación urbana. Ellos son vistos como oportunidad para proyectar las ciudades anfitrionas. Una profunda atracción en la planificación estratégica y el éxito del proceso de regeneración urbana obtenido en el marco de los Juegos Olímpicos de 1992 consiguieron llamar la atención de muchos agentes sobre el modelo Barcelona. De esa manera en este artículo se hace una discusión crítica sobre la transformación urbana experimentada por la ciudad catalán. Además se evalúa el impacto de los preparativos de Barcelona'92 en el acceso a la vivienda y en los desalojos de los grupos afectados. Se trata también de entender cómo la planificación estratégica impuesta en Barcelona impuso los proyectos, planes y programas derivadas de coaliciones públicas y privadas. Por lo tanto, este artículo analiza 
la trayectoria de las implicaciones socio-territoriales de los megaeventos deportivo español a través de una reflexión sobre todo geográfica.

Palabras clave: modelo Barcelona, megaeventos y desahucios, marketing urbano, planificación estratégica urbana.

Introdução

Com objetivo basilar de sediar os Jogos Olímpicos, a candidatura e as preparações de Barcelona'92 foram motivadas e cativadas, em parte, pelo desejo de expressar as realizações e o nacionalismo da comunidade catalã (Essex; Chalkley, 2003; Hargreaves, 2000). Passaram-se cerca de 70 anos desde que houve a precedente possibilidade de receber as edições dos Jogos no ano de 1924 pela Ciudad Condal.

Além disso, das Exposições Universais de 1888 e 1929 ao Forum Universal de las Culturas 2004 e ao projeto 22@Barcelona - El Districte de la Innovació, a cidade de Barcelona vem utilizando explicitamente ações estratégicas que culminaram em profundas transformações de caráter impregnadamente físico, político-ideológico e simbólico. O êxito de um planejamento estratégico orientado a reforçar a imagem da cidade e a emergência do fenômeno de regeneração urbana por meio, sobremaneira, dos Jogos Olímpicos de 1992, deflagraram o interesse de diversos agentes no modelo catalão. Entendê-lo era essencial para reproduzir tanto os elementos estratégicos quanto suas ideias-base, os quais levantaram também dilemas, polêmicas e questionamentos sobre sua eficácia ou ineficácia em outros territórios em intervenção.

No decorrer da história moderna dos Jogos Olímpicos, algumas cidades-sede têm se baseado numa busca incessante de reproduzir o processo de transformação urbana catalã mais do que outras sedes por diversos motivos. À vista disso, fatores econômicos em contextos locais e internacionais também têm desempenhado um papel fundamental na determinação dos níveis de investimento em infraestrutura e marketing urbano. Nesse sentido, qualificando-os como oportunidade de alcançar elementos estratégicos na agenda urbana, Hiller (2006) enfatiza que há outras lógicas envolvidas nas "tramas" em sediar um megaevento do que simplesmente oferecer instalações para competições desportivas. Em outras palavras, muita atenção vem sido dada às "falácias" do "impacto econômico e ao turismo em sediar as Olimpíadas” do que, simplesmente, manifestar o "espírito” esportivo e/ou proferir o legado de competição desportiva (p. 317-318). 
De fato, quando se realiza uma síntese histórica desses megaeventos esportivos, têm-se que, antes de 1960, as edições dos Jogos Olímpicos de Verão e as de Inverno eram consideradas eventos de escala relativamente pequena. Tratava-se de acontecimentos esportivos com "modestos investimentos em infraestrutura urbana" (Essex; Chalkley, 2003), além da construção de algumas instalações desportivas, quando não já existentes na cidade anfitriã. Desde 1960, ${ }^{1}$ os Jogos Olímpicos, precisamente os de Verão, começaram a incluir grandes transformações urbanas que têm se tornando ferramenta estratégica e tática de desenvolvimento regional, planejamento urbano e crescimento econômico. Conforme Horne (2007, p. 93), dentre os vários fatores aí preconizados, a intensa disputa entre cidades em sediar megaeventos esportivos ${ }^{2}$ notabilizou-se pelas seguintes teses:

i. Primeiro, a proliferação das novas tecnologias de comunicação e de massa, especialmente o desenvolvimento da televisão por satélite, posssibilitou precedentes audiências globais para eventos como as Olimpíadas e o Mundial de Futebol FIFA;

ii. Segundo, os megaeventos são vistos tanto como úteis para a venda de todos os tipos de produtos comerciais, quanto como oportunidades valiosas de promoção para as cidades-sede, reforçando a imagem de cidade e contribuindo ao turismo local e aos investimentos externos;

iii. Economicamente o megaevento, neste caso o esportivo, tem sido visto como uma "indústria lucrativa" em torno do qual as cidades-sede podem desenvolver estratégias de revitalização econômica local e regional, favorecendo o circuito superior de acumulação;

iv. Urbanisticamente, tais eventos vêm sendo propagados como mecanismos de impulso às intervenções de renovação urbana, gentrificação, flagship development e waterfront development etc.

De todo modo, os megaeventos esportivos, justamente as edições dos Jogos Olímpicos e as do Mundial de Futebol FIFA, passaram a constituir-se como catalisadores para megaprojetos de transformação urbana. Ora, de acordo com o Centre on Housing Rights and Evictions (COHRE), esses eventos igualmente vêm ocasionando impactos negativos sobre a questão do acesso à moradia nas cidades anfitriãs (COHRE, 2007). Infelizmente, observa-se desde os Jogos Olímpicos de Seul em 1988, o cresci- 
mento de remoções forçadas associadas às transformações produzidas sob o efeito combinado dos preparativos de megaeventos (esportivos), projetos de infraestrutura - urbana e desportiva -, impactos das violações de direitos humanos etc. No caso de Barcelona'92, a construção de instalações olímpicas e outros projetos associados afetaram mais de 600 famílias.

Assim posto, examinar como um megaevento esportivo, igualmente, ameaçou o direito à moradia das comunidades locais afetadas pelas transformações ocorridas durante as preparações de Barcelona'92, apresenta-se como instigante e precípuo. Neste sentido, este texto inicialmente trata da transformação urbana experimentada pela cidade de Barcelona no que toca concretamente ao planejamento estrategicamente orientado à regeneração urbana, ao modelo Barcelona e ao marketing de cidade, em suas dimensões múltiplas. A seção seguinte evoca os impactos das preparações desse megaevento no acesso à moradia, tanto na acessibilidade, quanto na disponibilidade de habitação em Barcelona e sua região metropolitana. Em seguida, os desalojos e as remoções dos grupos afetados com os Jogos Olímpicos de 1992 são postos em evidência, implicando refletir sobre as facetas relacionadas com a questão do acesso habitacional dos agentes envolvidos. Trata-se, enfim, de compreender como o planejamento estratégico esboçado em Barcelona impôs toda sorte de planos e programas resultantes de pactos políticos e privados. Em linhas gerais, cabe analisar a trajetória das implicações sócio-territoriais do megaevento esportivo em tela, traçada por meio de uma reflexão precipuamente geográfica.

De um projeto estratégico ao marketing urbano: o modelo Barcelona

Como resposta, grosso modo, à explosão populacional, as muralhas medievais começaram a ser demolidas em 1854. Após seis anos, era adotado o Plan de los Alrededores de la Ciudad de Barcelona y proyecto de su Reforma y Ensanche ${ }^{3}$ (ver Figura 1) de Idelfonso Cerdà. O assim conhecido Ensanche foi efetivamente concluído por volta da década de 1920. Nessa época já se notava certa preocupação elucidativa no que tange às imbricações da elaboração e direcionamento de políticas públicas urbanas como resposta ao adensamento populacional. Em razão disso, "houve um esforço criativo nas décadas de 1920 e 1930 para planejar o futuro crescimento urbano de Barcelona, no âmbito da Catalunha como um todo. A ideia, claramente inspirada em Ebenezer Howard, foi proposta em 1920 pela Societat Cívica La Ciutat Jardí” (Naylon, 1981, p. 231). 


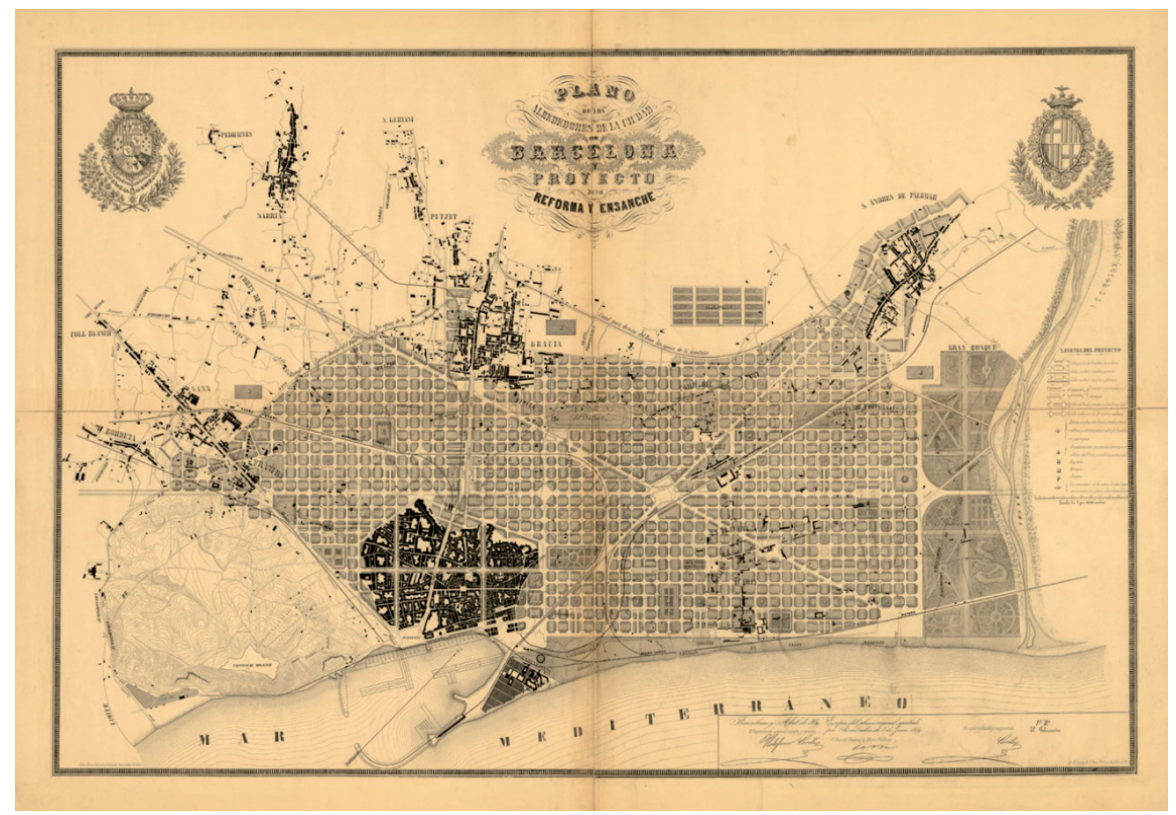

Figura 1 - Plan de los Alrededores de la Ciudad de Barcelona y proyecto de su Reforma y Ensanche, em 1861. Reprodução conforme o plano original de Ildefons Cerdà de 1859. Fonte: Instituto Cartogàfic de Catalunya.

De fato, a expansão urbana de Barcelona e seu planejamento espacial, igualmente, refletiam o clima político da Espanha de Franco4 entre os anos de 1939 e 1975. Cabe ressaltar que tal planejamento estava baseado num contexto gestado pelos conflitos entre os grupos políticos e classes sociais: "Barcelona é um exemplo do que pode acontecer quando o crescimento urbano é resultado do jogo descontrolado das forças do mercado, com empresários do setor privado acumulando resultados, desconsiderando os efeitos sociais" (Naylon, 1981, p. 224). A cidade se tornou um grande recinto de concentração urbano-regional no nordeste da Espanha, aglutinando atividades industriais e intensificando, consequentemente, os fluxos migratórios e a ampliação de sua área urbana.

Monclús (2010b) argumenta que a profunda e inegável transformação urbana experimentada nas últimas décadas do século XX por Barcelona foi irradiada pelo evento dos Jogos Olímpicos de 1992. Calcado no planejamento estratégico, em prol de uma cidade mais competitiva e 
atrativa, tal processo ficou marcado como "modelo Barcelona". De modo consequente, esse modelo tem sido referenciado e replicado em muitas outras cidades como um dos mais representativos planejamentos de cidade, reforçando tanto a tendência de competição entre cidades quanto o caráter das políticas públicas como ferramenta de suporte. A partir de então, o igualmente reconhecido "modelo de cidade compacta" (Busquets, 2004; Capel, 2009) fez com que a cidade catalã tenha "sido alvo da atenção internacional e tenha sido especificamente analisada a partir de diferentes perspectivas por economistas, geógrafos e planejadores urbanos" (Monclús, 2010b, p. 268).

Para Coaffee (2010, p. 186), em síntese,

o "modelo Barcelona" abrangeu vários recursos urbanísticos importantes que outros países, posteriormente, tentaram replicar. Estes incluíram visão e estratégia a longo prazo, excelência em urban design, bem como a importância de programas sociais bem financiados.

Dentro de uma esfera estritamente produtiva, almejava-se reconstruir um espírito de significação identitária da cidade e um sentido de apropriação do processo de reestruturação urbana, sobretudo, a partir dos anos 1980, período de redemocratização política espanhol. Notoriamente, tratava-se de uma série de intervenções espaciais por meio de um planejamento estratégico e operacional, abrindo caminho para um almejado desenvolvimento econômico e social, dentro de um alcance local e regional.

Além do mais, "a opinião que aparenta ser amplamente difundida é a que indica que o verdadeiro sucesso dos Jogos Olímpicos de Barcelona foi consequência da transformação vivida pela cidade, por meio de uma série de ações que, normalmente, tomam décadas e duraram apenas 6 anos" (Monclús, 2010b, p. 269). Neste sentido, o supracitado sucesso de Barcelona no que tange ao planejamento estrategicamente orientado à regeneração urbana por meio da organização dos Jogos Olímpicos teve profundas implicações para gestores e planejadores urbanos em todo o mundo. O maior impacto foi, provavelmente, no Reino Unido, onde a retórica em torno do urban renaissance contemporâneo acenou fortemente sobre a experiência de Barcelona: "este drive de política urbana se deve muito ao arquiteto Lord Richard Rogers que orientou os seafront developments em Barcelona” (Coaffee, 2010, p. 187). 
A partir do desejado objetivo de abrigar uma edição dos Jogos Olímpicos, defendia-se claramente que "los juegos fueron una excusa para atraer y concentrar infraestructuras en la ciudad y en su área metropolitana, con los objetivos de contrarrestar la crisis económica 1975-1980, que produjo un alto nivel de paro, así como para reducir el déficit de infraestructuras metropolitanas" (Clusa, 1999, p. 87). Com base nesta afirmação, as mudanças territoriais - que acompanharam a dinamização da nova espacialidade produzida a partir de Barcelona - expressavam a materialização sociotemporal da lógica e das ações estratégicas, operacionais e de gestão sobre a organização urbana e regional catalã.

Busquets (2004) reforça, contundentemente, a importância desse megaevento esportivo no desencadeamento de arranjos territoriais e urbanísticos em que a governança urbana teve papel essencial tanto nas dinâmicas espaciais quanto institucionais. Assume-se que tais arranjos foram engendrados pela implementação de projetos urbanos assentados estrategicamente em áreas "passíveis" de regeneração urbana, as quais estavam indicadas no Programa Olímpico para Barcelona'92.

Acompanhando esta dinâmica, alguns dos projetos de regeneração e intervenção espacial do programa urbanístico5 previsto para os Jogos de 1992começaram efetivamente em meados do ano de 1982, inclusive antes dos Jogos Olímpicos de Los Angeles em 1984 e da eleição da sede da XXV Olimpíada durante a 91 ${ }^{\text {a }}$ Sessão do Comitê Olímpico Internacional em 1986. Precisamente, formulado antes do verão europeu de 1986, o exprefeito Pasqual Maragall, à época, assumia a execução dos projetos urbanísticos, entre os quais estariam assegurados por investimentos garantidos nas premissas do mencionado programa (Busquets, 2004).

Portanto, ao suscitar o verdadeiro papel do estado sobre as mudanças contemporâneas no padrão territorial e nas alterações da política econômica no cenário urbano, Monclús (2010a) assevera que as Olimpíadas de 1992 foram usadas como um agente impulsionador para os projetos estratégicos de cidade e na dinâmica do território catalão. Dessa forma, as principais fontes de política urbana em Barcelona objetivavam tornar uma cidade mais competitiva e dinâmica, ressaltando os fenômenos de "place promotion" e regeneração urbana (Monclús, 2010b, p. 282). Contribuindo, assim, para novos padrões econômicos espaciais de produção e de consumo, sejam eles explícitos ou implícitos. 
Numa perspectiva relacionada à questão do capital simbólico, dos marcos de distinção e da renda monopolista,6 Harvey (2005) sustenta que, quando associados ao nome de cidades,7 eles possuem "um poder de atração importante em relação aos fluxos de capital de modo mais geral” (p. 233). Neste sentido, a partir de uma análise espacial marxista e de viés anglo-saxão, o autor evoca a cidade de Barcelona como a grande beneficiada da renda monopolista vinculada ao capital simbólico, dentro de uma busca incessante ao acúmulo dos marcos de distinção:

enfatizou-se a prospecção da história e da tradição caracteristicamente catalã, o marketing a respeito de suas importantes realizações artísticas e heranças arquitetônicas (Gaudí, é claro), e seus marcos distintivos de estilo de vida e tradições literárias, com o apoio de uma avalanche de publicações, exibições e eventos culturais celebrantes da distinção. Além disso, houve novos embelezamentos arquitetônicos (a antena de radiocomunicação de Norman Foster, o Museu de Arte Moderna branco fulgurante de Meier, no meio de construções degradadas da cidade velha), investimentos pesados para permitir o fácil acesso ao porto e à praia, recuperando terrenos baldios para a Vila Olímpica [...], e a transformação do que fora antes uma vida noturna lúgubre e perigosa num panorama aberto de espetáculo urbano. (Harvey, 2005, p. 233-234)

Junto com a implementação de planos estratégicos concebidos como parte de um impulso urbano, Barcelona perdeu alguns dos seus marcos de distinção e incorporou sinais "nada sutis de disneificação" (Harvey, 2005, p. 234). Refletindo até que ponto, determinados elementos urbanísticos e especulativos se tornam poderosas ferramentas constitutivas do empreendedorismo urbano, Harvey explana que “[...] o capital simbólico coletivo acumulado por Barcelona [dependia] dos valores de autenticidade, singularidade e qualidades específicas irreplicáveis”.

No que se refere às fases posteriores ao modelo Barcelona'92, Harvey (2005, p. 235) salienta que o "capital simbólico coletivo de Barcelona enquanto cidade" estava relacionado à renda monopolista dentro de uma feroz competição global, encabeçada por uma "arquitetura de grife". A este respeito, deve-se mencionar o poder comandado pela governança urbana, em que as rendas monopolistas são conquistadas pelos diversos marcos de distinção. Sendo um objeto do fetiche capitalista, a renda monopolista é realçada pela apropriação capitalista por meio do multiculturalismo, do monumental, da moda, da estética e do espetáculo (Harvey, 2005). Por conseguinte, seja ela intencional e funcional, “a renda monopo- 
lista sempre é um objeto do desejo capitalista, os meios de obtê-la através de intervenções nos campos da cultura, história, patrimônio, estética e significados deve necessariamente ser de grande importância para os capitalistas de todos os tipos" (p. 237).

Obviamente, o modelo de planejamento estratégico e de recuperação urbana aplicado em Barcelona foi revertido em subsídios irresistíveis ao mercado imobiliário, aos incorporadores e outros agentes seletos. Entretanto, segundo Muñoz (2006), as supostas lições socioespaciais do Programa Olímpico de 1992 não foram totalmente positivas por duas razões principais:

i. Em primeiro lugar, o processo de regeneração urbana aumentou consideravelmente o preço da moradia nas décadas posteriores aos Jogos Olímpicos de 1992. Trata-se de um processo que foi estendido a toda a cidade, tornando muito difícil a acessibilidade de habitação (social) para a população local. Como consequência dessa infeliz realidade, em que se privilegiou agentes seletos, um número muito importante de famílias deixou a cidade para morar em outros municípios metropolitanos.

ii. Em segundo lugar, simultaneamente a esse processo, a renovação de diversas áreas para a promoção turística da cidade evidenciou um processo muito intenso de especialização das atividades ligadas direta e indiretamente com a economia mundial do turismo.

Ademais, Muñoz (2006) pondera que o sucesso da capital catalã como destino turístico teve efetivamente um atributo positivo, não só em termos econômicos como financeiros. Contudo, a meta inicial de alcançar uma cidade diversificada e integrada, aparentemente, tanto em termos socioespaciais quanto socioeconômicos não foi totalmente cumprida. Não há divergências quanto à façanha do retrocitado modelo engendrado por Barcelona, porém os efeitos perversos também se fizeram presentes por meio de uma distribuição de espaços de gentrificação, segregação, exclusão e desterritorialização.

No que tange ao período pós-Barcelona'92, precisamente por volta de 1996, "a preocupação da cidade em ser [constantemente] referência internacional levou a gestão municipal a planejar o Proyecto Fórum Mundial de las Culturas para o ano de 2004 na região de Besós. [...] Pretende-se, desta vez, criar um novo tipo de evento - sob os auspícios da Unesco - que 
trate da diversidade cultural, do ámbito da paz e cidade sustentável” (Busquets, 2004, p. 430). O consórcio de gestão do evento foi composto por membros do Estado Espanhol, da Generalitat (Governo) de Catalunha e da Prefeitura de Barcelona (Clusa, 1999).

Ora, a área remodelada para sediar o evento Forum Universal de las Culturas8 em 2004 evidenciou, igualmente, uma relativa ausência de qualidade dos projetos de arquitetura (Busquets, 2004). Tal espacialidade, regenerada, a qual engendrou um "novo bairro e centro marítimo em Barcelona" (Bohigas, 2004), situa-se entre os bairros de Diagonal Mar i el Front Marítim del Poblenou, El Besòs i el Maresme e Poblenou: a nova paisagem revelada ao longo da orla da cidade espanhola "lembra uma espécie de desenvolvimento urbanístico de segunda mão à Florida, altamente desconectado da paisagem urbana e cultura local, reproduzida em um curto espaço de tempo, a qual gerou fortes divergências entre os habitantes locais" (Muñoz, 2006, p. 183).

Reproduzido num curto espaço de tempo, o evento Forum Universal de las Culturas gerou expressivos desacordos entre os habitantes locais e representou novamente algumas das ambições daquele "urbanismo olímpico" de 1992: "encontrar o equilíbrio entre o sucesso na arena global e soluções para os problemas sociais locais é hoje, assim como era em 1992, o principal desafio para a cidade" (Muñoz, 2006, p. 183).

Nesse período pós-olímpico, uma série de outros projetos infraestruturais e de renovações urbanas foram levados a cabo. Neste sentido, Clusa (1999) critica o uso de "megaeventos" como marco estratégico, pelo qual, recentes transformações urbanas redefiniram o uso e o acesso do território. O dinamismo urbanístico e especulativo em expansão comandou o emprego de áreas extremamente seletivas nesse território, cuja ambiência favoreceu a instituição de espaços produtivos turísticos, inovativos, culturais e criativos nos distritos de San Martí (ver Figura 2) e Ciutat Vella. Tais áreas receberam uma enxurrada de projetos e programas urbanísticos, remodelando espaços preteritamente industriais e periféricos. Dentre eles, urge levar em conta o Plan de Barrios, projeto Barcelona Key, e outros projetos URBAN, financiados com fundos europeus.

Merece mencionar, também, a articulação funcional de produção e consumo verificada corroborou, noutro modelo de megaprojeto de transformação socioespacial e econômica pari passu, a formação de um novo cluster de inovação tecnológica: o 22@, igualmente conhecido como22@Barcelona e Districte de la innovació. Sendo uma iniciativa municipal, ele surge 
no ano de 2000 visando incorporar 200 hectares de áreas preteritamente industriais do Poblenou em um bairro produtivo inovador. Pretendendo, deste modo, viabilizar estrategicamente espaços modernos para a implantação e concentração de empresas de inovações científicas e tecnológicas.

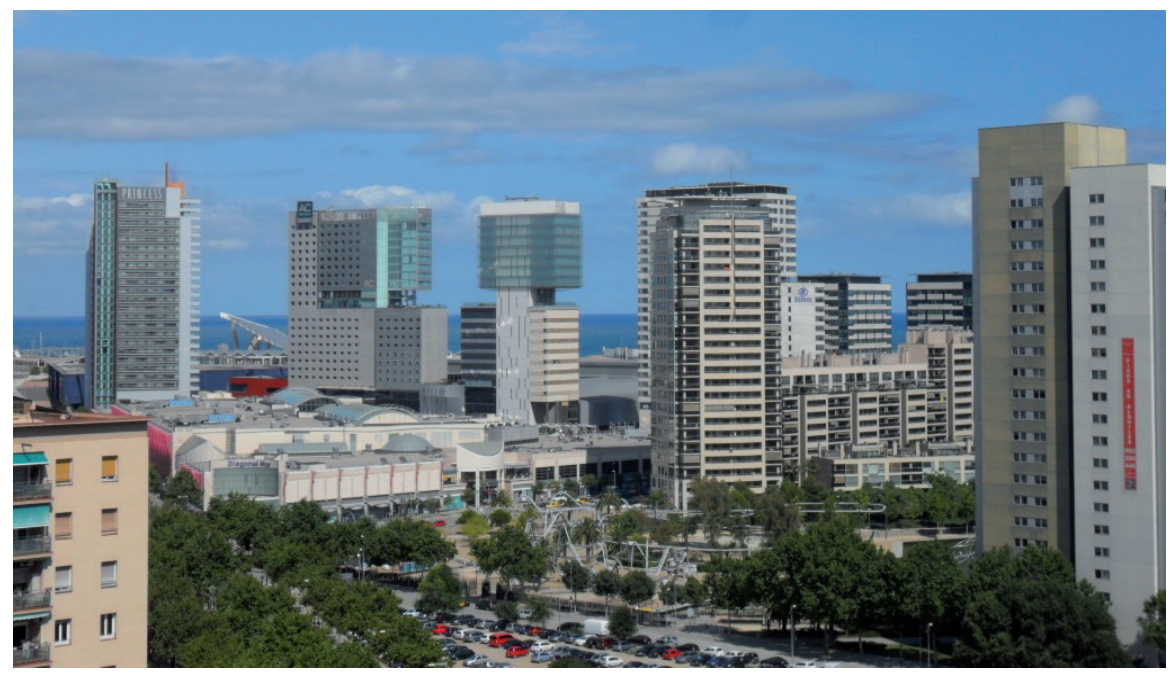

Figura 2 - Área Forum (ao fundo), entre Diagonal Mar i el Front Marítim del Poblenou e El Besòs i el Maresme, distrito de San Martí, na zona nordeste de Barcelona, em 2011.

Os impactos negativos de um megaevento esportivo no acesso à moradia

De um lado, empenhada à capitalização do espaço. Do outro, com vistas à reconversão de seu perfil socioeconômico e turístico, tornando-o mais competitivo. Vista desta perspectiva, mediante investimentos maciços em infraestrutura, Barcelona teve um papel catalisador de esquemas de revitalização espacial: gentrificação, urbanismo empresarial, espetacularização e marketing urbano etc. A cidade engendrou tais esquemas, num processo cada vez mais controlado pelos arranjos do capital hegemônico e por meio da adoção de uma receita de planejamento urbano, dito estratégico. Na sequência, portanto, as "tramas" foram desmanchadas e as "falácias” são descobertas: a valorização imobiliária acompanhou sobremodo tal dinamismo, viabilizando espaços excludentes, dificultando e represando o acesso à moradia. 
Neste sentido, a realização dos Jogos Olímpicos de 1992 teve um impacto tal-qualmente negativo na acessibilidade e disponibilidade de habitação em Barcelona e sua região metropolitana. Segundo levantamento do Centre on Housing Rights and Evictions (COHRE) e do Observatório DESC (2007), entre os anos de 1986 e 1992 -, período de preparação para as Olimpíadas -, o preço da moradia aumentou consideravelmente na cidade espanhola. Constatou-se um aumento de cerca de $240 \%$ nos preços dos imóveis novos entre o anúncio de 1986, da eleição de Barcelona como cidade-sede e 1992, ano de celebração dos Jogos Olímpicos. Unidades habitacionais destinadas, preferencialmente, ao aluguel social foram reduzidas. Mais que isso, a construção de novas habitações de interesse social encolheu consideravelmente.

Além disso, cabe citar a ausência de políticas de habitação social voltadas à proteção dos grupos menos favorecidos e, por consequência, afetados, sobremodo, pelo megaevento esportivo. Aliás, muitas pessoas foram deslocadas. Aproximadamente 624 famílias foram desalojadas das áreas designadas como zonas olímpicas ou daquelas associadas ao recebimento de obras de construção de empreendimentos desportivos e/ou urbanos. Contudo, urge levar em conta que, durante a preparação de Barcelona'92, unidades habitacionais foram ofertadas para as famílias afetadas pelas intervenções e pelos empreendimentos previstos. Assim mesmo, mecanismos de compensação foram instituídos mediante negociação entre os afetados e organizações institucionais.

\section{Encarecimento do preço da moradia}

Merece destaque evidenciar que, "a partir dos anos 80 até o presente, Barcelona tem sido caracterizada por um desejo de internacionalização através da organização de diversos eventos de impacto global, e da organização de feiras e congressos" (Pareja, 2010, p. 138). A cidade delineou (re)ajustes espaciais buscando projeção internacional através de uma carregada promoção publicitária - e propagandista - com o reforço de cenários aos "rituais" de produção, consumo e das parcerias públicas e privadas; contudo,“tornando-se difícil saber quem são os verdadeiros agentes e quais são estratégias” (Carreras, 1994, p. 113).

Parafraseando Queirós (2010), urge refletir sobre a importância dessa estratégia territorial e empresarial por meio de transformações 
urbanas nas "tramas" de uma burguesia "abanderada" de posições e de discursos ideológicos-simbólicos, capitalistas e seletivos. Em síntese, "Barcelona é hoje o centro nevrálgico de uma rede de cidades. A sua economia de serviços está em processo de expansão, embora ainda com forte representação da indústria, a base econômica tradicional da cidade e da sua envolvente metropolitana." (Queirós, 2010, p. 13). Assim, a "força motriz urbana” na cidade de Barcelona foi um epicentro estratégico, sobremaneira, imbuído de arranjos espaciais (re)produzidos sob a instituição de espaços de gentrificação, regeneração e segregação urbana.

Conforme colocado por Muñoz (2006), o processo de regeneração urbana empreendido por Barcelona aumentou o preço da moradia no período imediatamente posterior a Barcelona'92. Fenônemo que dificultou o acesso à habitação e impulsionou fluxos migratórios dentro da Área Metropolitana de Barcelona.

Neste sentido, dado seu caráter desigual de produção do espaço, o resultante encarecimento do solo acarretou um impacto significativo sobre o acesso da população local à habitação a preços acessíveis. Durante o período de preparação aos Jogos Olímpicos de 1992, depreendeu-se um aumento em torno de $139 \%$ e $149 \%$, nos preços da habitação e do aluguel, respectivamente (Observatório DESC, 2007).

Iniciado a partir da segunda metade da década de 1980, o dito encarecimento no preço da habitação foi considerado um dos maiores impactos do persuasivo crescimento urbano na capital catalã (Tello; Martinez, 1994, p. 61). Até 1992, os preços dos imóveis subiram excessivamente, duplicando de valores. Fenômeno que não aconteceu em meados de 1976, quando da aprovação do Plano Geral de Ordenamento Urbano da Área Metropolitana de Barcelona. O plano, conforme Valls (1998, p. 34),

disminuía substancialmente la edificabilidad global, aproximadamente en un $25 \%$, y afectaba de equipamientos y zonas verdes a muchos solares que quedaban por edificar. Esto produjo una fuerte demanda de licencias de edificación con los estándares antiguos, licencias para las que existía interés en agotar el plazo de dos años para la obra, plazo que se prolongó luego con otro dos más. Es decir que viviendas según los antiguos estándares continuaban entrando en un mercado ya saturado incluso a principios de los $80 .^{9}$

Os preços de mercado para novos imóveis elevaram-se, gerando especulações nos distritos e bairros da cidade. Houve uma redução na disponibilidade de imóveis para aluguel e, além do mais, não houve polí- 
ticas públicas de habitação dirigidas aos grupos menos favorecidos, quais sejam: imigrantes, migrantes, sem-teto, famílias de ciganos etc.

Entre 1986 e 1992 o número de novas casas para venda em Barcelona aumentou quase 101\%. Este aumento, longe de viabilizar o acesso à moradia, teve um impacto negativo na acessibilidade, refletindo também um encarecimento significativo dos preços de venda de novas unidades residenciais. Como resultado da nova regulamentação sobre aluguéis, os valores das unidades habitacionais para alugar, semelhantemente, elevaram-se no período acima citado.

Entre 1986 e 1993 (anos pós-Jogos Olímpicos), o aumento acumulado foi quase $145 \%$ nos preços de novos imóveis. Ao mesmo tempo, a oferta de casas de aluguel diminuiu gradualmente: entre 1981 e 1991, houve uma diminuição de 23,69\%. A disponibilidade de moradia pública e social foi drasticamente reduzida: entre 1986 e 1992, havia uma cumulativa redução em torno de $75.92 \%$ em habitação pública disponível. Ora, enquanto os Jogos Olímpicos ajudaram a promover a marca "Barcelona" como um destino turístico internacional, eles favoreceram significativamente - via valorização imobiliária -, o preço da habitação na cidade homônima.

\section{Remoções}

Ora, mesmo que grande parte das instalações olímpicas fora construída em áreas "supostamente" não residenciais, os projetos urbanísticos afetaram um total de 282 famílias, ver Tabela 1. Tais projetos suprimiram 4 comunidades nos distritos de San Martí e Montjuïc: La Perona, Camp de La Bota, Transcementiri e Can Valero Petit. Os projetos de mobilidade deslocaram aproximadamente 195 famílias. Além disso, 147 foram removidas no bairro Poblenou em função da construção da Vila Olímpica. O relatório Barcelona 1992: International Events and Housing Rights: a Focus on the Olympic Games, é enfático em concluir que grande parte das remoções não foi forçada, bem como os processos de realojamento dos grupos afetados viabilizaram unidades habitacionais adequadas e/ou houve compensação ou indenização financeira.

Três principais áreas foram alvo de despejos: uma primeira área envolve um conjunto de bairros nas proximidades da Vila Olímpica; uma segunda área compreende a área onde se encontra a colina Montjuïc (onde estava localizado o Estádio Olímpico e outras instalações desportivas); 
e uma terceira área incluía os bairros onde foram implantados os novos anéis viários (denominados de rondas, em espanhol).

Tabela 1 - Localização das comunidades e número de famílias afetadas com o megaevento de 1992.

\begin{tabular}{|c|c|c|c|}
\hline Projetos & \multicolumn{2}{|l|}{ Comunidades } & $\begin{array}{c}\text { Número de } \\
\text { famílias } \\
\text { afetadas }\end{array}$ \\
\hline $\begin{array}{l}\text { Construção da Vila } \\
\text { Olímpica }\end{array}$ & \multicolumn{2}{|l|}{ Remoções no Poblenou } & 147 \\
\hline \multirow{2}{*}{$\begin{array}{l}\text { Construção de } \\
\text { anéis viários } \\
\text { (Ronda de Dalt) }\end{array}$} & \multicolumn{2}{|c|}{ Remoção da comunidade Bloque Fantasma } & 65 \\
\hline & \multicolumn{2}{|c|}{$\begin{array}{l}\text { Remoção da comunidade Las Casas del } \\
\text { Comandante }\end{array}$} & 18 \\
\hline \multirow{2}{*}{$\begin{array}{l}\text { Conexões com os } \\
\text { anéis viários fora } \\
\text { de Barcelona }\end{array}$} & \multicolumn{2}{|c|}{$\begin{array}{l}\text { Remoção da comunidade La Pata Norte } \\
\text { (Santa Coloma de Gramanet) }\end{array}$} & 52 \\
\hline & \multicolumn{2}{|c|}{$\begin{array}{l}\text { Remoção da comunidade La Pata Sul } \\
\text { (L'Hospitalet de Llobregat) }\end{array}$} & 60 \\
\hline \multirow{4}{*}{$\begin{array}{l}\text { Projetos de } \\
\text { renovação } \\
\text { urbanística }\end{array}$} & \multirow{3}{*}{ Distrito de Sant Martí } & $\begin{array}{l}\text { Remoção da } \\
\text { comunidade } L a \\
\text { Perona } \\
\end{array}$ & 102 \\
\hline & & $\begin{array}{l}\text { Remoção da } \\
\text { comunidade Camp } \\
\text { de La Bota }\end{array}$ & 60 \\
\hline & & $\begin{array}{l}\text { Remoção da } \\
\text { comunidade } \\
\text { Transcementiri } \\
\end{array}$ & 100 \\
\hline & Distrito de Montjuïc & $\begin{array}{l}\text { Remoção da } \\
\text { comunidade Can } \\
\text { Valero Petit } \\
\end{array}$ & 20 \\
\hline \multicolumn{3}{|l|}{ Total } & 624 \\
\hline
\end{tabular}

Fonte: Observatório DESC (2007). Elaboração própria.

A construção e/ou ampliação dos anéis viários com vistas à melhoria da mobilidade urbana em Barcelona e no acesso ao entorno metropolitano estava previsto no Programa Olímpico para 1992. A implementação das Rondas facilitava igualmente os fluxos de circulação aos locais de competição - distribuídos em quatro áreas olímpicas - que foram usadas nos Jogos Olímpicos de Verão de 1992. Para tanto, quatro comunidades foram 
totalmente deslocadas com as obras da Ronda de Dalt: Bloque Fantasma, Las Casas del Comandante, La Pata Norte (localizada nos limites do município de Santa Coloma de Gramanet) e La Pata Sul (nos limites metropolitanos de L’Hospitalet de Llobregat).

\section{Considerações finais}

A construção e a implementação de instalações olímpicas e outras infraestruturas associadas à Barcelona'92 afetaram 624 famílias. Dado este, que reforçou as estatísticas de remoções desencadeadas através de megaeventos esportivos e por meio da viabilização de megaprojetos de transformação e regeneração urbana. Ora, irradiado pelas Olimpíadas, o planejamento estratégico e operacional esboçado na capital catalã impôs toda sorte de arranjos espaciais e econômicos de produção e consumo. Além disso, também não se pode esquecer que houve um encarecimento de cerca de $240 \%$ nos preços dos imóveis entre 1986 e 1992. A essa situação, deve-se agregar o contingente populacional "desalojado" e/ou "desapropriado" que fora obrigado a instalar-se em áreas periféricas onde os preços do solo e da moradia eram mais acessíveis.

Consequentemente, a cidade foi beneficiada pela renda monopolista vinculada ao capital simbólico e hegemônico. Mesmo perdendo os seus marcos originais de distinção, os objetos urbanísticos e especulativos se tornaram poderosas ferramentas constitutivas do empreendedorismo urbano em Barcelona, os quais foram impulsionados sobremaneira pelo fenômeno do megaevento. Assim sendo, o arquétipo de planejamento estratégico e de requalificação urbana aplicados na cidade e entorno - vulgo modelo Barcelona - foi revertido em subsídios irresistíveis ao mercado imobiliário, aos incorporadores e outros agentes seletos no modo de produção capitalista.

Obviamente, há que se considerar a façanha do modelo engendrado por Barcelona. No entanto, a meta inicial a fim de alcançar uma cidade diversificada e integrada socioespacialmente e economicamente não foi totalmente sustentada. De todo modo, os efeitos perversos na estrutura socioespacial também se fizeram presentes por meio de uma distribuição de espaços de gentrificação, segregação, exclusão e desterritorialização. As novas espacialidades "regeneradas" privilegiaram somente alguns agentes que, ao incorporar projetos pelos quais evocaram um dinamismo urbanístico e especulativo em expansão, comandaram a reterritorialização de 
áreas extremamente seletivas, cuja ambiência favoreceu a instituição de espaços produtivos turísticos, culturais e criativos.

Deve-se ter em vista que, mesmo ganhando muito adeptos, a concepção de padrões e estratégias do modelo barcelonês acarretou a elevação do preço do solo e das unidades habitacionais. Com efeito, o processo vertiginoso de valorização imobiliária acompanhou sobremodo tal dinamismo, viabilizando espaços excludentes, dificultando e represando o acesso à moradia e o direito à cidade. Por fim, vale apontar que, geralmente, tais espaços vinculam-se aos interesses do capital hegemônico e não aos da maioria social. Uma vez desocupados, converteram-se tanto em áreas de retenção quanto de apropriação imobiliária na cidade-sede dos Jogos Olímpicos de 1992.

\section{Notas}

1. Em 1960, a cidade de Roma sediou os Jogos Olímpicos de Verão. Houve investimentos em infraestrutura desportiva e urbana: a título de exemplo, Aeroporto Internazionale Leonardo da Vinci di Fiumicino, conhecido como Aeroporto di Fiumicino, e foi concebido em função do megaevento.

2. Aqui, pode-se mencionar tanto as edições dos Jogos Olímpicos, quanto as da Copa do Mundo de Futebol FIFA; e aquelas de menor escala, tais como: Jogos Pan-americanos e Jogos da Commonwealth etc.

3. O Plan de los Alrededores de la Ciudad de Barcelona y proyecto de su Reforma y Ensanche proposto por Ildefons Cerdà i Sunye tinha, inicialmente, como objetivo precípuo criar uma nova cidade moderna - durante a nova era industrial -, expandida (Ensanche em español e em catalão, l'Eixample) e de ilimitada previsão de crescimento por meio de um traçado ortogonal com blocos quadriculares em formato de octógonos.

4. A ditadura militar franquista foi um período que vigorou na Espanha por cerca de 37 anos, cujas bases precípuas estavam associadas ao nacionalismo, conservadorismo, catolicismo e ao anticomunismo. Caracterizou-se, sobretudo, pela violação dos direitos humanos, força radical e forte repressão aos opositores do regime militar. Após a Segunda Guerra Mundial, a política econômica de tal sistema recebeu expressiva ajuda finaceira dos Estados Unidos da América durante a Guerra Fria.

5. De fato, o período "oficial" de preparação para os Jogos da XXV da Olimpíada em Barcelona, situou-se entre 1986 e 1992, em que foram postos em prática os demais projetos de transformação espacial e desportiva do Programa Olímpico para 1992.

6. Renda monopolista "[...] é uma abstração advinda da linguagem da economia política. Para os mais interessados em questões de cultura, estética, valores afetivos, vida social e coração, esse termo talvez seja muito técnico e árido para suportar o peso dos assuntos humanos, além dos possíveis cálculos dos finan- 
cistas, dos incorporadores, dos especuladores imobiliários e dos locadores" (Harvey, 2005, p. 221).

7. "O capital simbólico coletivo vinculado a nomes e lugares como Paris, Atenas, Nova York, Rio de Janeiro, Berlim e Roma é de grande importância, conferindo a tais lugares grandes vantagens econômicas em relação a, por exemplo, Baltimore, Liverpool, Essen, Lille e Glasgow" (Harvey, 2005, p. 233).

8. O ex-prefeito de Barcelona, Pascual Maragall, confirmava em 17 de outubro de 1996 o evento, cuja celebração em 2004 coincidia com o aniversário de 75 anos da Exposição de 1929.

9. "Diminuiu substancialmente a área total de construção, cerca de $25 \%$, e afetou equipamentos e muitas áreas verdes e solares que ainda não tinham sido contruídos. Isso produziu uma forte procura de licenças de construção para os antigos padrões, licenças para as quais os juros foram esgotados no prazo de dois anos para a construção, o prazo foi então prorrogado por mais dois. Isto é, as unidades habitacionais de acordo com os antigos padrões permaneciam num mercado já saturado, mesmo no início dos anos 80” (Tradução nossa).

\section{Referências}

BUSQUETS, J. Barcelona: la construcción urbanística de una ciudad compacta. Barcelona: Ediciones del Serbal, 2004.

BOHIGAS, O. Contra la incontinencia urbana: reconsideración moral de la arquitectura y la ciudad. Barcelona: Electa, 2004.

CAPEL, H. El modelo Barcelona: un examen crítico. 2. ed. Barcelona: Ediciones del Serbal, 2009.

CARRERAS, C. Os novos espaços de consumo em Barcelona. Finisterra, Revista Portuguesa de Geografia, v. XXIV, n. 57, p. 103-117, 1994.

COHRE. Centre on Housing Rights and Evictions. Fair play for housing rights: mega-events, olympic games and housing rights. Geneva: COHRE, 2007.

CLUSA, J. La experiencia olímpica de Barcelona 1986-1992 y las expectativas del Forum 2004. Cidades, v. 5, p. 85-102, 1999.

COAFFEE, J. Urban regeneration and renewal. In: GOLD, J. R.; GOLD, M. Olympic cities: city agendas, planning and the World's games, 1896-2016. London and New York: Routledge, 2010.

ESSEX, S.; CHALKLEY, B. Las transformaciones urbanas a raíz de la celebración de los Juegos Olímpicos: lecciones universitarias olímpicas. Barcelona: Centre d'Estudis Olímpics (UAB)/Cátedra Internacional de Olimpismo (CIO-UAB), 2003.

HARGREAVES, J. Freedom for Catalonia? Catalan nationalism, Spanish identity, and the Barcelona Olympic Games. Cambridge: Cambridge University Press, 2000.

HARVEY, D. A produção capitalista do espaço. Tradução de Carlos Szlak. São Paulo: Annablume, 2005. (Coleção Geografias e Adjacências). 
HILLER, H. H. Post-event outcomes and the post-modern turn: the olympics and urban transformations. European Sport Management Quarterly, v. 6, n. 4, p. 317332, 2006.

HORNE, J. The four 'knowns' of sports mega-events. Leisure Studies, v. 26, n. 1, p. 81-96, 2007.

MONCLÚS FRAGA, F. J. Urbanismo olímpico y postolímpico. Visiones profesionales, académicas y periodísticas. Biblio 3W. Revista Bibliográfica de Geografía y Ciencias Sociales, Universidad de Barcelona, v. XV, n. 895 (3), 2010a. Disponível em: < http:/www.ub.es/geocrit/b3w-895/b3w-895-3.htm>. Acesso em: 9 dez. 2010.

. Barcelona 1992. In: GOLD, J. R.; GOLD, M. Olympic cities: city agendas, planning and the world's games, 1896-2016. London and New York: Routledge, 2010b.

MUÑOZ, F. Olympic urbanism and olympic villages: planning strategies in olympic host cities, London 1908 to London 2012. Sociological Review, v. 54, s2, p. 175-187, 2006.

NAYLON, J. Barcelona. In: PACIONE, M. Urban problems and planning in the developed world. London: Croom Helm, 1981.

OBSERVATÓRIO DESC. Barcelona 1992: international events and housing rights: a focus on the olympic games. Ginebra: COHRE, 2007.

PAREJA EASTAWAY, M. El regime de tenencia de la vivienda en España. In: MALDONADO LEAL, J. (Coord.). La política de vivienda en España. Madrid: Editorial Pablo Iglesias, 2010.

QUEIRÓS, M. Barcelona(s). Cidades dos projetos ou projetos da cidade? Finisterra, Revista Portuguesa de Geografia, v. XLV, n. 90, p. 7-32, 2010.

TELLO, R.; MARTINEZ RIGOL, S. Terciarização e encarecimento do alojamento em Barcelona. Finisterra, Revista Portuguesa de Geografia, v. XXIV, n. 57, p. 6177, 1994.

VALLS PLA, J. El precio de compra venda de viviendas en Barcelona (1972-1996). In: VERGÉS, R. (Ed.). El precio de la vivienda y la formación del hogar. Barcelona: Centre de Cultura Comtemporània de Barcelona, 1998.

Ernandy Luis Vasconcelos de Lima - Possui Graduação em Geografia pela Universidade Estadual do Ceará. Mestrado em Desenvolvimento e Meio Ambiente pela Universidade Federal do Ceará e em Planificación Territorial y Gestión Ambiental pela Universitat de Barcelona. Doutorado em Geografía, Planificación Territorial y Gestión Ambiental pela Universitat de Barcelona e Pós-Doutorado pela University of Oxford.

Este artigo foi revisado por Janaynne Carvalho do Amaral, revisora textual da Divisão de Periódicos do CEGRAF - Centro Editorial e Gráfico UFG. 